Case Reports in
Gastroenterology
Case Rep Gastroenterol 2021;15:92-96

DOI: 10.1159/000509952

Published online: January 26, 2021

(c) 2021 The Author(s)

OPEN

Published by S. Karger AG, Basel

This article is licensed under the Creative Commons Attribution-NonCommercial 4.0 International License (CC BY-NC) (http://www.karger.com/Services/OpenAccessLicense). Usage and distribution for commercial purposes requires written permission.

\title{
Recurrent Encephalopathy and Severe Anion Gap Metabolic Acidosis in a Patient with Short Bowel: It Is D-Lactic Acidosis
}

\author{
Avni Jain Kiran Jhinger Jonathon Bellas \\ Department of Internal Medicine, Max Rady College of Medicine, Rady Faculty of Health \\ Sciences, University of Manitoba, Winnipeg, MB, Canada
}

\section{Keywords}

Short bowel syndrome $\cdot$ Complications $\cdot$ Obesity-bariatric surgery $\cdot$ D-lactic acidosis

\begin{abstract}
D-lactic acidosis is a rare and potentially underrecognized condition in patients with short bowel syndrome. We present the case of a 61-year-old female with a history of an ileojejunal bypass at age 18 who presented to hospital with acute-onset encephalopathy, ataxia, and severe anion gap metabolic acidosis (AGMA). On initial investigations there were no identifiable etiologies for the AGMA. Further history revealed that she had been experiencing these symptoms on a recurrent basis for the past 40 years. An oral carbohydrate load was given to the patient in hospital which reproduced her symptoms and the AGMA. A serum D-lactate level returned elevated several weeks later. A 2-month follow-up revealed that all her symptoms had ceased with limitation of carbohydrates to $150 \mathrm{~g}$ per day. Patients with short bowel syndrome are susceptible to developing D-lactic acidosis due to the large carbohydrate loads that are delivered to the colon, where they are then metabolized. Due to its rarity, it is likely that there is a delay in recognition of this condition. This case report describes a common clinical presentation of this rare condition and describes the pathophysiology, diagnosis, and management of $D$-lactic acidosis in small bowel syndrome.

(C) 2021 The Author(s)

Published by S. Karger AG, Basel
\end{abstract}

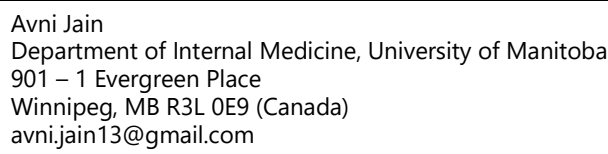




\section{Case Reports in Gastroenterology}

\begin{tabular}{l|l}
\hline Case Rep Gastroenterol 2021;15:92-96 \\
\hline DOI: 10.1159/000509952 & $\begin{array}{l}\text { @ 2021 The Author(s). Published by S. Karger AG, Basel } \\
\text { www.karger.com/crg }\end{array}$ \\
\hline
\end{tabular}

Jain et al.: D-Lactic Acidosis as a Complication of Short Bowel Syndrome

\section{Introduction}

\section{Biochemistry and Metabolism}

Lactic acidosis is a well-known cause of anion gap metabolic acidosis (AGMA). Lactic acid is composed of two enantiomers, L-lactic and D-lactic acid [1]; however, only L-lactic acid (in the form of lactate) is usually identifiable in clinical laboratories. D-lactate levels require specific laboratory testing which are not widely available and take several weeks to yield a result. Acidosis due to L-lactate accumulation most commonly results from anaerobic glycolysis secondary to tissue hypoxia [2], and L-lactate is rapidly metabolized to pyruvate by L-lactate dehydrogenase in the liver [3]. D-lactate, however, is a product of bacterial metabolism of fermented carbohydrates and can accumulate when malabsorbed carbohydrates are delivered to the colon in large quantities $[4,5]$. It circulates in the bloodstream for longer than L-lactate because of a lack of D-lactate dehydrogenase in mammals. D-lactate is metabolized by d- $\alpha$-hydroxy acid dehydrogenase, which metabolizes at one-fifth of the rate of L-lactate [6]. Therefore, D-lactic acidosis produces severe AGMA, without an apparent responsible anion seen in routine bloodwork.

\section{D-Lactic Acidosis}

The colon is usually protected from large carbohydrate loads by the means of gastric emptying regulation and digestion in the small intestine. In patients who have short bowel syndrome secondary to bariatric surgery, there is a large influx of carbohydrates to the colon following a meal due to loss of these protective mechanisms. Colonic bacteria metabolize these carbohydrates to produce L- and D-lactate, of which L-lactate is rapidly cleared from the circulation [7] and D-lactate accumulates.

The clinical presentation of this condition often includes encephalopathy, slurred speech, ataxic gait, and Kussmaul breathing [1]. The definitive mechanism by which elevated D-lactate levels produces neurologic symptoms has been hypothesized, but remains largely unknown [7].

\section{Case Presentation}

We present the case of a 61-year-old female, otherwise healthy, who was brought to the hospital with acute-onset encephalopathy, ataxia, and slurred speech. Her medical history was significant for non-small-cell lung cancer, for which she had underwent a lobectomy in 2015. She also had had a bariatric ileojejunal bypass at the age of 18 , following which she had suffered chronic diarrhea.

The patient reported feeling well the morning prior. She went out for a late lunch and had a large bowl of noodles. A few hours later she began to feel very fatigued and went to bed early. She then woke up at 02:00 $\mathrm{h}$ to go to the bathroom, lost her balance on the way, and fell. Her husband noticed that she was confused and slurring her words and immediately alerted the emergency medical services out of concern that his wife was having a stroke.

On presentation to hospital, she was assessed by the emergency physician and was found to be confused, dysarthric, and ataxic. She had no other focal neurologic findings and the remainder of her examination was normal.

Her initial blood work showed a wide anion gap of 24 and metabolic acidosis (pH 7.15, $\mathrm{HCO}_{3} 12, \mathrm{pCO}_{2} 33$ ), with entirely normal renal function, liver function, glucose, beta-hydroxy-

\section{Karger'=}




\section{Case Reports in Gastroenterology}

Case Rep Gastroenterol 2021;15:92-96 DOI: $10.1159 / 000509952$

(c) 2021 The Author(s). Published by S. Karger AG, Basel www.karger.com/crg

Jain et al.: D-Lactic Acidosis as a Complication of Short Bowel Syndrome

butyrate, and serum osmolality. She also had a negative toxic screen for alcohol and salicylates. A computed tomography scan of her brain and cerebrospinal fluid testing were unremarkable. The Neurology service was consulted and suggested empiric treatment for herpes simplex virus encephalitis. Magnetic resonance imaging of her brain along with an electroencephalogram were subsequently ordered and returned normal. Further investigation results are shown below.

The patient was admitted to the Internal Medicine service, by which time she had already had considerable improvement in her clinical status. Her confusion, slurred speech, and ataxia had all resolved by the morning, as had her acid-base status. Further history revealed that she had experienced similar episodes before. In fact, the confusion, slurred speech, and ataxia had been occurring 4 or 5 times per week for the last 40 years. These episodes would usually occur in the evening after supper, following which she would go to bed early, and by the time she woke up, she would be asymptomatic. She was unable to identify specific triggers for these episodes.

While in hospital, she was eventually given a carbohydrate load with scheduled blood work every $4 \mathrm{~h}$. Shortly after, she developed an AGMA and had recurrence of her presenting symptoms. These were self-limiting over the next $8 \mathrm{~h}$. A D-lactate level was sent, and the patient was discharged with instructions to limit her carbohydrate intake to $100-120 \mathrm{~g}$ per day and to return to hospital if her symptoms recurred.

Four weeks later, she was seen in follow-up and her D-lactate had returned elevated at $9 \mathrm{mmol} / \mathrm{L}$ (upper limit of normal is $0.3 \mathrm{mmol} / \mathrm{L}$ ). She had been compliant with restricting her carbohydrate intake and had not had recurrence of any of her symptoms, for the first time in 40 years. Her chronic diarrhea had also resolved and she had regained 10 pounds.

\section{Discussion and Conclusion}

In clinical practice, it is possible that D-lactic acidosis is underrecognized. Symptom onset can be months to years following gastrointestinal surgery or onset of a malabsorption syndrome. In this case, the patient had tolerated recurrent neurologic symptoms for over 40 years without investigation by a physician. A study published in 1985 [8] aimed to assess the prevalence of D-lactic acidosis in patients who had undergone ileojejunal bypass compared with individuals with no history of gastrointestinal surgery. Out of the 33 patients who underwent bypass, 16 (48\%) reported having experienced symptoms that were considered consistent with D-lactate encephalopathy (i.e., dizziness, dysarthria, confusion, memory loss, headache, weakness) postoperatively. Of the 16 patients reporting a history of symptoms, 9 (56\%) had D-lactate levels $>0.5 \mathrm{mmol} / \mathrm{L}$ in a random serum sample (range $0.7-11.5 \mathrm{mmol} / \mathrm{L}$ ). For a controlled comparison, serum samples were taken from a total of 157 individuals including healthy, obese, and those with Crohn's disease, none of whom had a positive D-lactate result $(>0.5 \mathrm{mmol} / \mathrm{L})$. This study illustrates the correlation between bariatric bypass surgery, elevated D-lactate levels, and neurologic symptoms consistent with D-lactic acidosis.

Three mainstay approaches to management have been identified for patients with a diagnosis of D-lactic acidosis. These include restriction of carbohydrate intake, oral administration of poorly absorbed antibiotics (such as metronidazole, neomycin, or vancomycin) elimination of colonic microbiota, and electrolyte or acid-base correction (via dialysis) [1]. Other treatment options such as probiotic supplementation to reduce bacterial overgrowth have been speculated but lack supporting evidence [9].

\section{Karger'=}




\section{Case Reports in Gastroenterology}

This case highlights the rare condition of D-lactic acidosis and its clinical significance in patients with short bowel syndrome. It is important to consider this complications as part of the differential diagnosis of AGMA in patients who have undergone gastrointestinal bypass surgery or have a malabsorption syndrome.

\section{Statement of Ethics}

The patient described in this case report provided informed written and signed consent to publication of her case. There is no information revealing the patient's identity in this paper. The paper was written with ethical considerations in accordance with the World Medical Association Declaration of Helsinki.

\section{Conflict of Interest Statement}

The authors have no conflicts of interest to declare.

\section{Funding Sources}

The authors have no funding sources to declare.

\section{Author Contributions}

A. Jain was the author responsible for the initial draft of the manuscript. K. Jhinger and J. Bellas were responsible for further revising the manuscript. All authors agreement on the final draft of the manuscript.

\section{References}

1 Bianchetti DG, Amelio GS, Lava SA, Bianchetti MG, Simonetti GD, Agostoni C, et al. D-lactic acidosis in humans: systematic literature review. Pediatr Nephrol. 2018 Apr;33(4):673-81.

2 Adeva-Andany M, López-Ojén M, Funcasta-Calderón R, Ameneiros-Rodríguez E, Donapetry-García C, Vila-Altesor M, et al. Comprehensive review on lactate metabolism in human health. Mitochondrion. 2014 Jul;17:76-100.

3 Ewaschuk JB, Naylor JM, Zello GA. D-lactate in human and ruminant metabolism. J Nutr. 2005 Jul;135(7): 1619-25.

4 Fabian E, Kramer L, Siebert F, Högenauer C, Raggam RB, Wenzl H, et al. D-lactic acidosis - case report and review of the literature. Z Gastroenterol. 2017 Jan;55(1):75-82.

5 Halperin ML, Kamel KS. D-lactic acidosis: turning sugar into acids in the gastrointestinal tract. Kidney Int. 1996 Jan;49(1):1-8.

6 Tubbs PK. The metabolism of D-alpha-hydroxy acids in animal tissues. Ann N Y Acad Sci. 1965 Jul;119(3): 920-6.

7 Kang KP, Lee S, Kang SK. D-lactic acidosis in humans: review of update. Electrolyte Blood Press. 2006 Mar;4(1):53-6.

8 Thurn JR, Pierpont GL, Ludvigsen CW, Eckfeldt JH. D-lactate encephalopathy. Am J Med. 1985 Dec; 79(6):717-21.

\section{Karger'=}


9 Uchida H, Yamamoto H, Kisaki Y, Fujino J, Ishimaru Y, Ikeda H. D-lactic acidosis in short-bowel syndrome managed with antibiotics and probiotics. J Pediatr Surg. 2004 Apr;39(4):634-6. 